\title{
Analytical reliability analysis of soil-water characteristic curve
}

\author{
A.Johari ${ }^{1, a}$, A. Hooshmand Nejad ${ }^{1}$, A.A. Javadi ${ }^{2}$ \\ ${ }^{1}$ Department of Civil and Environmental Engineering, Shiraz University of Technology, Shiraz, Iran \\ ${ }^{2}$ Computational Geomechanics Group, College of Engineering, Mathematics and Physical Sciences, University of Exeter, Exeter, \\ EX4 4QF, UK
}

\begin{abstract}
The Soil Water Characteristic Curve (SWCC), also known as the soil water-retention curve, is an important part of any constitutive relationship for unsaturated soils. Deterministic assessment of SWCC has received considerable attention in the past few years. However the uncertainties of the parameters which affect SWCC dictate that the problem is of a probabilistic nature rather than being deterministic. In this research, a Gene Expression Programming (GEP)-based SWCC model is employed to assess the reliability of SWCC. For this purpose, the Jointly Distributed Random Variables (JDRV) method is used as an analytical method for reliability analysis. All input parameters of the model which are initial void ratio, initial water content, silt and clay contents are set to be stochastic and modelled using truncated normal probability density functions. The results are compared with those of the Monte Carlo (MC) simulation. It is shown that the initial water content is the most effective parameter in SWCC.
\end{abstract}

\section{Introduction}

The success of any unsaturated analysis like unsaturated slope stability greatly depends on the input data such as SWCC that defines the relationship between the amount of water in a soil (i.e. gravimetric water content $\mathrm{w}$, volumetric water content $\theta$ or degree of saturation $\mathrm{S}$ and matric suction $\psi[1])$.

Many empirical equations have been proposed to curve fit the SWCC [2-7]. Another approach is to estimate the SWCC from the grainsize distribution curve [8,9]. The other method is artificial intelligence methods to predict the SWCC such as artificial Neural Network (ANN) [10], Genetic-Based Neural Network (GBNN)[11], Genetic programming (GP)[11], evolutionary polynomial regression (EPR)[12], and Gene Expression Programming (GEP) [13]. These methods use some basic soil properties to predict the SWCC, instead of some time consuming tests such as pressure plate test.

Reliability analysis is an area of growing importance in geotechnical engineering. The success of numerical modelling of geotechnical systems

\footnotetext{
a Ali Johari : johari@sutech.ac.ir
}

greatly depends on the uncertainty modelling, among which uncertainty in soil properties is a crucial input of the analysis.

Most of the previous statistical studies on the SWCC-fitting parameters focus on the mean, standard deviation, and coefficient of variation [14]. Some researchers observed the correlations between curve fitting parameters for hydraulic properties of unsaturated soils[15]. The grain size distributions is used to estimate SWCC curves and the SWCC parameters are determined graphically from the curves [16]. This work results in a mean and standard deviation for each SWCC parameter. It was attempted to construct a joint probability distribution function for the van Genuchten, (1980) parameters [17]. The key step is to relate the empirical joint nonnormal distribution of the van Genuchten, (1980) parameters to a standard joint normal distribution. When the experimental data on hand is restricted to only marginal distributions and correlations, this translation approach is popular [18]. The suitability of a lognormal random vector in predicting the parameters of van Genuchten, (1980) model was demonstrated [19]. As well as this, The Bayesian analysis is applied to derive the PDF of the model 
parameters in various forms of van Genuchten equation using the observed data of sand, sandy loam and silty loam [20].

Most of previous reliability analysis of SWCC focuses on SWCC-fitting models. However, in this research the reliability analysis of an artificial intelligence model of SWCC with acceptable accuracy is performed. The reliability analysis is regarding to uncertainties of independent input parameters of model which are based on grain size distribution curve and inherent soil properties. This analysis is carried out at different suctions using an analytical method and results were verified by Monte Carlo simulation (MCs).

\section{Corresponding SWCC model used for reliability analysis}

In this research, one of the artificial intelligence models is selected for reliability analysis. The model which is namely GEP model [13] has acceptable accuracy to predict the SWCC. Table 1 shows the correlation coefficient and error values of this model to predict the SWCC based on SoilVision (2002) databank which contains more than 180 pressure plate tests results performed on clay, silty clay, sandy loam, and loam soil.

Table 1. Performance of GEP model ( Johari and Hooshmand , 2015)

\begin{tabular}{|c|c|c|c|c|c|c|}
\hline & \multicolumn{3}{|c|}{ Training Data } & \multicolumn{3}{c|}{ Testing Data } \\
\hline Model & ARE (\%) & MSSE & $\mathrm{R}^{2}$ & ARE (\%) & MSSE & $\mathrm{R}^{2}$ \\
\hline GEP & 25.59 & 0.0014 & 0.94 & 28.73 & 0.0014 & 0.94 \\
\hline
\end{tabular}

GEP model use the soil properties as inputs to predict SWCC and does not use the curve-fitting parameters. The Johari and Hooshmand (2015) GEP model for predicting soil-water characteristic curve is as the following:

$$
\omega=\frac{-1}{S+2 \mathrm{Cl}-2.202 \frac{\mathrm{S}^{4}}{\mathrm{Cl}^{2}}-7.285}-\omega_{0}\left(\mathrm{~S}+0.062(\mathrm{Si}+\mathrm{e})^{2}-1\right)
$$

Where:

$$
\begin{array}{ll}
\mathrm{e} & \text { Initial void ratio; } \\
\omega_{0} & \text { Initial water content } \\
\mathrm{S} & \log \left[\text { suction }(\mathrm{kPa}) / \mathrm{p}_{\mathrm{a}} \text { ] where } \mathrm{pa}=\right. \\
\text { Atmospheric pressure }(\text { taken as } 100 \mathrm{kPa})
\end{array}
$$
$\mathrm{Cl} \quad$ Clay content $(\%)$
$\mathrm{Si} \quad$ Silt content (\%)
$\omega \quad$ Predicted gravimetric water content

The comprehensive explanation of this method is available in Johari and Hooshmand (2015), however, Fig. 1. Shows a prediction of SWCC by GEP model for a typical soil sample of databank with the following properties: Void ratio: 0.71; Initial water content: $26.89 \%$; Clay content $28.71 \%$; Silt content: $63.57 \%$.

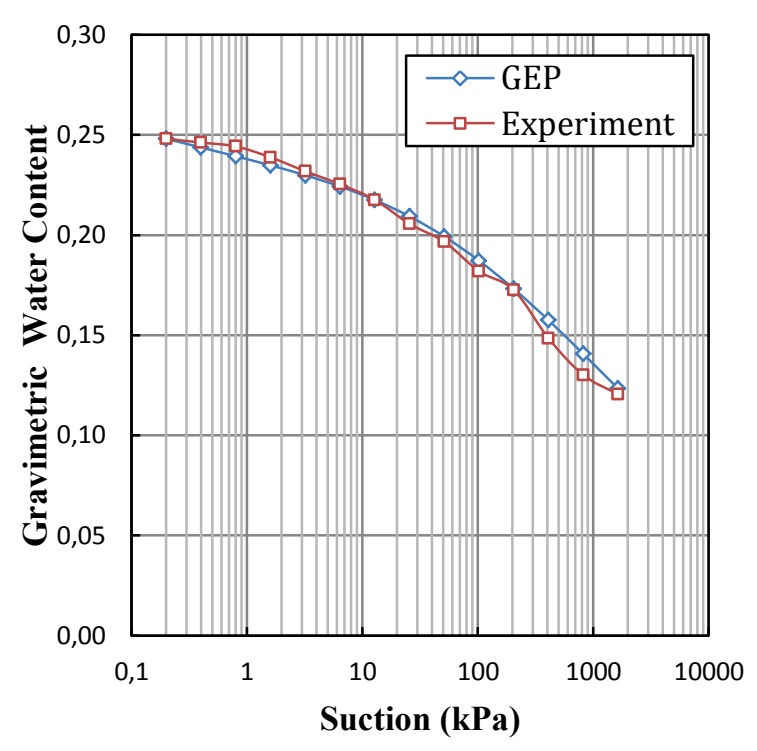

Figure 1. A typical SWCC prediction of GEP model

\section{Reliability analysis of SWCC by JDRV method}

Jointly Distributed Random Variables (JDRV) method is an analytical probabilistic method. In this method probability density function of input variables are expressed mathematically and jointed together by statistical relations [21-23]. Due to the nature of analytical methods, utilizing this method for some geotechnical problems with complex governing relationships may require complicated analysis and a single expression in this method may become rather complex. Some recent researches have been made to apply this method to geotechnical problems [24-26].

The GEP model of SWCC has five input parameters namely void ratio, initial water content, logarithm of suction normalized with respect to atmospheric air pressure, clay content and silt content. To account for the uncertainties in soil-water 
characteristic curve, all four input parameters have been defined as stochastic variables at every specific suctions of SWCC. Therefore, selected parameters are void ratio (e), initial water content $\left(\omega_{0}\right)$, clay content $(\mathrm{Cl})$, and silt content $(\mathrm{Si})$. All of these parameters are modeled using a truncated normal probability distribution function (pdf).

By considering the stochastic variables within the range of their mean plus or minus four times standard deviation, $99.994 \%$ of the area beneath the normal density curve is covered.

For reliability assessment of soil-water characteristic curve using JDRV method, Eq. (1) is rewritten into terms of $K_{1}$ to $K_{11}$ as shown in Eq. (2). The terms $K_{1}$ to $K_{11}$, are introduced in Eq. (3). The probability density function of each term is derived separately. Using the mathematical functions for $\mathrm{K}_{1}$ to $\mathrm{K}_{11}$ and $\mathrm{fK}_{1}\left(\mathrm{k}_{1}\right)$ to $\mathrm{fK}_{11}\left(\mathrm{k}_{11}\right)$ a computer program was developed (coded in MATLAB) to determine the probability density function curve of SWCC.

$$
\begin{aligned}
& \frac{-1}{\mathrm{k}_{7}+2 \mathrm{k}_{4}}-\mathrm{k}_{3}\left(\mathrm{~S}+0.062 \mathrm{k}_{1}^{2}-1\right)= \\
& \frac{-1}{\mathrm{k}_{7}+\mathrm{k}_{8}}-\left(\mathrm{k}_{3} \times \mathrm{k}_{5}\right)=\mathrm{k}_{10}-\mathrm{k}_{6}=\omega
\end{aligned}
$$

Where:

$$
\left\{\begin{array}{l}
k_{1}=S i+e \\
k_{2}=0.062 k_{1}^{2} \\
k_{3}=\omega_{0} \\
k_{4}=C l \\
k_{5}=k_{2}+S-1 \\
k_{6}=k_{3} \times k_{5} \\
k_{7}=S-7.285-\frac{2.202 S^{4}}{k_{4}^{2}} \\
k_{8}=2 k_{4} \\
k_{9}=k_{7}+k_{8} \\
k_{10}=\frac{-1}{k_{9}} \\
k_{11}=k_{10}-k_{6}
\end{array}\right.
$$

In addition, for comparison, determination of the SWCC using the Monte Carlo simulation was also coded in the same computer program. In order to verify the results of the presented method with those of the Monte Carlo simulation, the final probability density function for gravimetric water content are showed for the same suction $(3.0 \mathrm{kPa})$. Fig. 2 shows the obtained probability density function of gravimetric water. Table 2 presents the properties of obtained gravimetric water content distribution resulted from JDRV and MCs which are perfectly compatible.

Table. 2. Properties of gravimetric water content distribution from JDRV and MCs

\begin{tabular}{|c|c|c|c|c|}
\hline Method & Mean & Mode & Variance & Skewness \\
\hline JDRV & 0.5224 & 0.5353 & 0.0337 & 1.0676 \\
\hline MCs & 0.5115 & 0.5349 & 0.0334 & 1.0740 \\
\hline
\end{tabular}

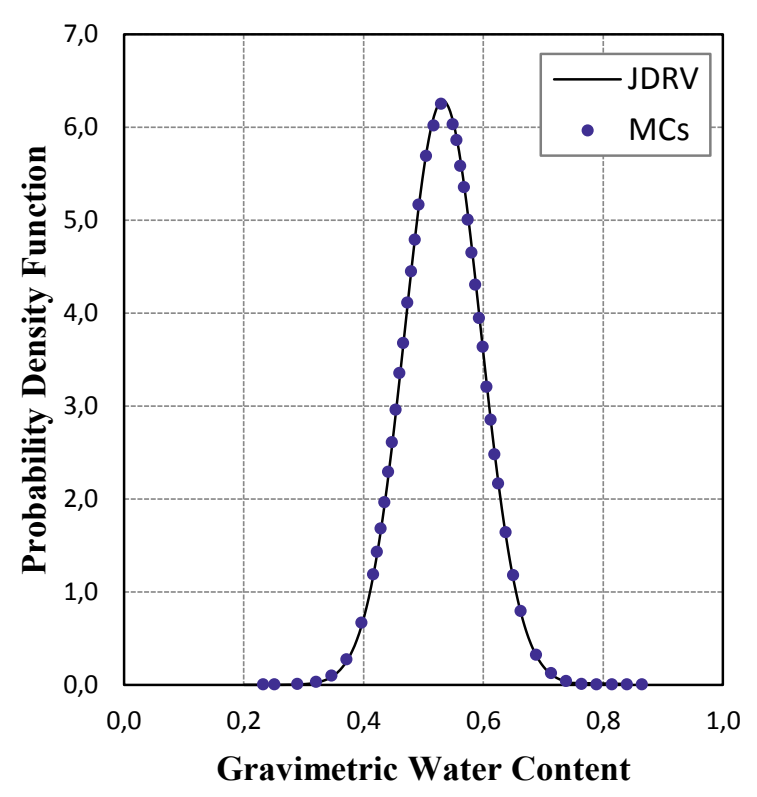

Figure 2. Probability density function of gravimetric water content at $3.0 \mathrm{kPa}$ suction

\subsection{Reliability analysis of SWCC at various suctions}

Probability density functions of gravimetric water content in various suctions (from $0.2 \mathrm{kPa}$ to 52428.8 $\mathrm{kPa}$ ) are shown in Fig. 3.Ten arbitrary suctions from $0.2 \mathrm{kPa}$ are selected where each one four times as much increased relative to previous one. The $2 \mathrm{D}$ plot of probability density functions of gravimetric water content are shown in Fig. 4. It is clear that increasing suction cause decrease in gravimetric water content, therefore, the pdf shifted leftward. It can be seen that 
the sample with lower suction has a greater dispersion (more uncertainties) of gravimetric water content.

Fig. 5 shows the distribution of gravimetric water content at various suctions that initiate from 0.2 $\mathrm{kPa}$ and doubled until $104857.6 \mathrm{kPa}$. Normal distribution of SWCC, in fact is pdf of gravimetric water content at different suctions. Two boundaries are shown in this figure which are the upper bound and lower bound of gravimetric water content at the specific suction. The values of lower bound is the limit of minimum gravimetric water content at each suction and similarly, upper bound shows the limit for maximum of gravimetric water content. It can be seen that the distance between the upper and lower bound (D) is decreased as the suction increase. Furthermore, the mean curve consists of gravimetric water contents values that have cumulative density equal to $\% 50$ at considered suctions, which in fact correspond with the peak of pdf diagram. The values of upper bound, lower bound, mean and 'D' are given in Table 3.

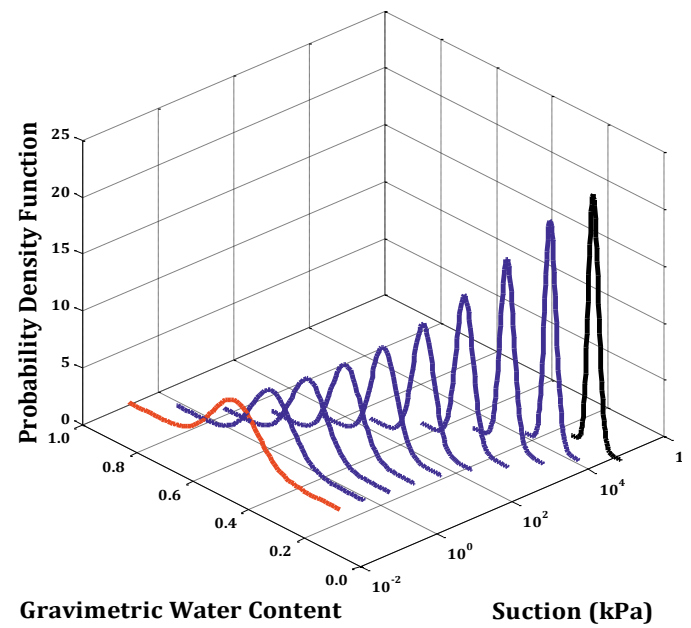

Figure 3. Probability density function of gravimetric water content in various suctions

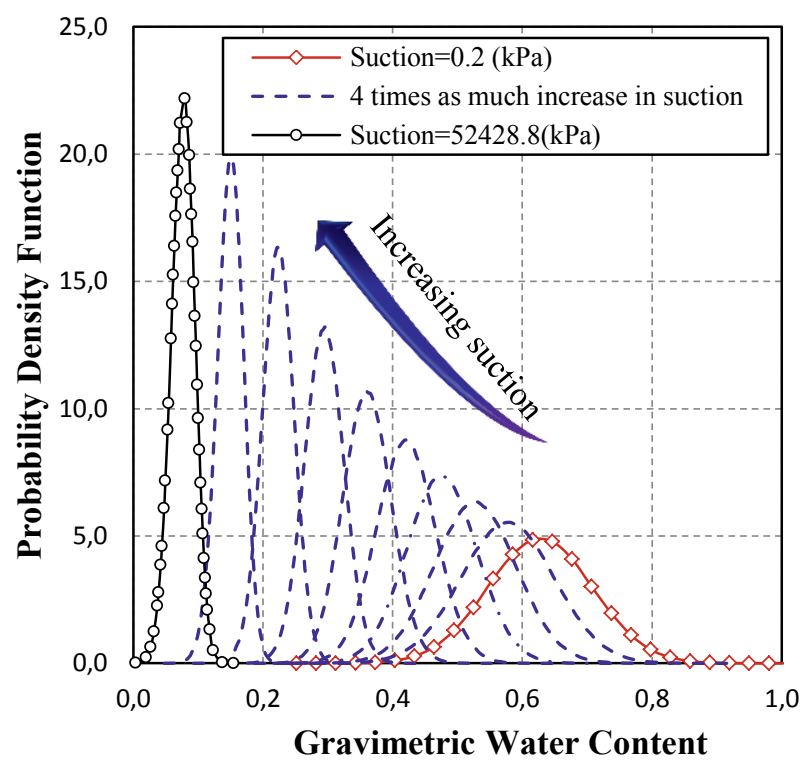

Figure 4. Probability density function of gravimetric water content in various suctions

\section{Conclusion}

In this research, a Gene Expression Programming (GEP)-based SWCC model is employed to assess the reliability of SWCC. For this purpose, the Jointly Distributed Random Variables (JDRV) method is used as an analytical method for reliability analysis. Uncertainties in SWCC can be evaluated in terms of the uncertainties in geotechnical input parameters. To account for the uncertainties in SWCC, all input parameters of GEP model which are initial void ratio, initial water content, silt and clay content have been defined as stochastic variables at every specific suctions of SWCC. The results showed that the determined probability density function of SWCC by JDRV method as analytical approach is very close to prediction of the Monte Carlo simulation. Furthermore, the upper bound, lower bound and the mean value of gravimetric water content at various suctions are determined. It can be seen that the determined probability distribution of gravimetric water content has greater dispersion (more uncertainty) in lower suctions. 


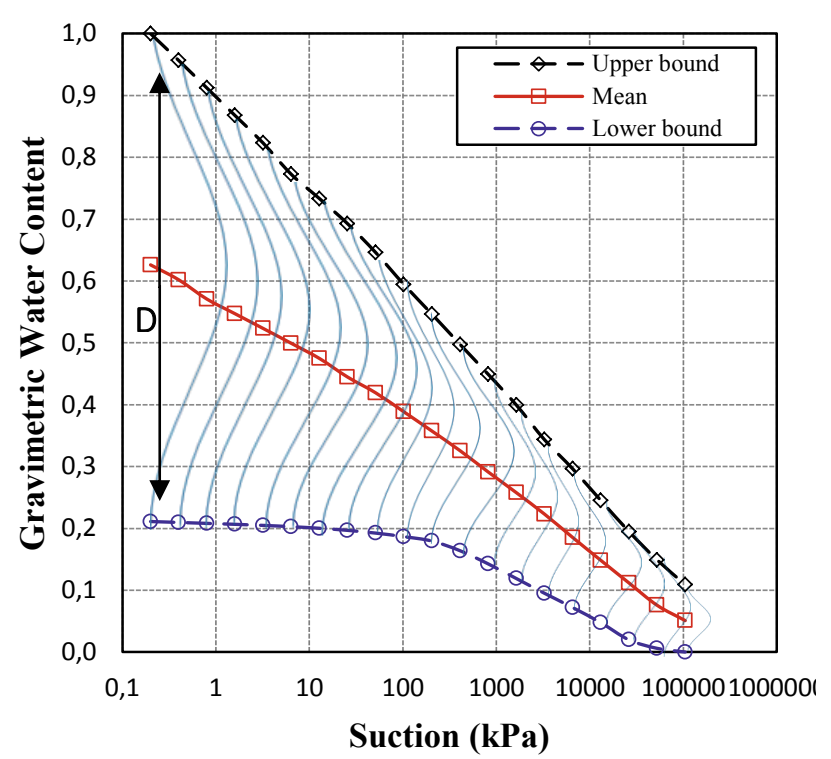

Figure 5. Boundaries of predicted initial drying curve

Table 3. Values of boundaries, mean and distance boundaries gravimetric water content for initial drying

\begin{tabular}{|c|c|c|c|c|}
\hline $\begin{array}{c}\text { Suction } \\
(\mathbf{k P a})\end{array}$ & $\begin{array}{c}\text { Upper } \\
\text { bound }\end{array}$ & Mean & $\begin{array}{c}\text { Lower } \\
\text { bound }\end{array}$ & $\mathbf{D}$ \\
\hline 0.2 & 1.000 & 0.614 & 0.234 & 0.766 \\
\hline 0.4 & 0.986 & 0.589 & 0.231 & 0.755 \\
\hline 0.8 & 0.938 & 0.565 & 0.228 & 0.710 \\
\hline 1.6 & 0.891 & 0.541 & 0.225 & 0.666 \\
\hline 3.2 & 0.843 & 0.516 & 0.221 & 0.622 \\
\hline 6.4 & 0.7946 & 0.492 & 0.218 & 0.5766 \\
\hline 12.8 & 0.746 & 0.466 & 0.213 & 0.533 \\
\hline 25.6 & 0.681 & 0.439 & 0.208 & 0.473 \\
\hline 51.2 & 0.645 & 0.412 & 0.201 & 0.444 \\
\hline 102.4 & 0.592 & 0.383 & 0.193 & 0.399 \\
\hline 204.8 & 0.538 & 0.354 & 0.181 & 0.357 \\
\hline 409.6 & 0.4873 & 0.321 & 0.159 & 0.3283 \\
\hline 819.2 & 0.432 & 0.289 & 0.134 & 0.298 \\
\hline 1638.4 & 0.382 & 0.254 & 0.111 & 0.271 \\
\hline 3276.8 & 0.330 & 0.218 & 0.09 & 0.240 \\
\hline 6553.6 & 0.279 & 0.184 & 0.07 & 0.209 \\
\hline 13107.2 & 0.232 & 0.148 & 0.045 & 0.187 \\
\hline 26214.4 & 0.190 & 0.111 & 0.020 & 0.170 \\
\hline 52428.8 & 0.150 & 0.076 & 0.001 & 0.150 \\
\hline 104857.6 & 0.117 & 0.042 & 0.000 & 0.117 \\
\hline
\end{tabular}

\section{References}

1. D. G. Fredlund and H. Rahardjo, Soil mechanics for unsaturated soils. John Wiley \& Sons, (1993).

2. R. H. Brooks and A. T. Corey, Hydraulic Properties of Porous Media. Colorado State University, (1964).

3. D. G. Fredlund and A. Xing, "Equations for the soil-water characteristic curve," Can. Geotech. J., vol. 31, no. 4, pp. 521-532, (1994).

4. W. R. Gardner, "Some steady-state solutions of the unsaturated moisture flow equation with application to evaporation from a water table," Soil Sci., vol. 85, no. 4, pp. 228-232, (1958).

5. C. R. McKee and A. C. Bumb, "The importance of unsaturated flow parameters in designing a monitoring system for hazardous wastes and environmental emergencies," in Proc. Hazardous Materials Control Research Institute Natl. Conf., Houston, TX, pp. 50-58, (1984).

6. M. T. van Genuchten, "A Closed-form Equation for Predicting the Hydraulic Conductivity of Unsaturated Soils1," Soil Sci. Soc. Am. J., vol. 44, no. 5, p. 892, (1980).

7. J. Williams, R. E. Prebble, W. T. Williams, and C. T. Hignett, "The influence of texture, structure and clay mineralogy on the soil moisture characteristic," Soil Res., vol. 21, no. 1, pp. 15-32, (1983).

8. L. M. Arya and J. F. Paris, "A physicoempirical model to predict the soil moisture characteristic from particle-size distribution and bulk density data," Soil Sci. Soc. Am. J., vol. 45, no. 6, pp. 1023-1030, (1981).

[9] M. D. Fredlund, D. G. Fredlund, and G. W. Wilson, "Prediction of the soil-water characteristic curve from grain-size distribution and volume-mass properties," in Proc., 3rd Brazilian Symp. on Unsaturated Soils,( 1997), vol. 1, pp. 13-23.

10. A. Johari and A. A. Javadi, "Prediction of a soil-water characteristic curve using neural network," 5thInternationalConference Unsaturated Soils Barrcelona Spain, vol. 1, pp. 461-466, (2011).

11. A. Johari, G. Habibagahi, and A. Ghahramani, "Prediction of soil-water characteristic curve using a genetic based neural network," Sci. Iran., vol. 13, no. 3, pp. 284-294, (2006).

12. A. Ahangar-Asr, A. Johari, and A. A. Javadi, "An evolutionary approach to modelling the soil-water characteristic curve in unsaturated 
soils," Comput. Geosci., vol. 43, pp. 25-33, Jun. (2012).

13. A. Johari and A. Hooshmandnejad, "Prediction of soil-water characteristic curve using gene expression programming," Iran. J. Sci. Technol. Trans. Civ. Eng., vol. 39, no. C1, (2015).

14. W. S. Sillers and D. G. Fredlund, "Statistical assessment of soil-water characteristic curve models for geotechnical engineering," Can. Geotech. J., vol. 38, no. 6, pp. 1297-1313, (Dec. 2001).

15. R. G. Hills, D. B. Hudson, and P. J. Wierenga, "Spatial variability at the Las Cruces trench site," Indirect Methods Estim. Hydraul. Prop. Unsaturated Soils Univ Calif. Riverside, pp. 529-538, (1992).

16. M. Fredlund, G. F. N. Gitirana, Jr., and H. Pham, "A methodology for applying probability theory to unsaturated hydraulic proper- ties for seepage analysis," Proc GeoCongress 2008 Chall. Sustain. Geoenvironment Geotech. Spec. Publi- Cation 178 ASCE Rest. Va, (2008).

17. R. F. Carsel and R. S. Parrish, "Developing joint probability distributions of soil water retention characteristics," Water Resour. Res., vol. 24, no. 5, pp. 755-769, (1988).

18. K.-K. Phoon, "Modeling and simulation of stochastic data," in GeoCongress 2006@ sGeotechnical Engineering in the Information Technology Age, pp. 1-17, (2006).

19. K.-K. Phoon, A. Santoso, and S.-T. Quek, "Probabilistic analysis of soil-water characteristic curves," J. Geotech. Geoenvironmental Eng., vol. 136, no. 3, pp. 445-455, (2010).

20. C. F. Chiu, W. M. Yan, and K.-V. Yuen, "Reliability analysis of soil-water characteristics curve and its application to slope stability analysis," Eng. Geol., vol. 135136, pp. 83-91, (May 2012).

21. P. G. Hoel, S. C. Port, and C. J. Stone, Introduction to Statistical Theory. HoughtonMifflin, (1971).

22. K. M. Ramachandran and C. P. Tsokos, Mathematical Statistics with Applications. Academic Press, (2009).

23. H. Tijms, Understanding Probability: Chance Rules in Everyday Life. Cambridge University Press, (2007).

24. A. Johari and A. A. Javadi, "Reliability assessment of infinite slope stability using the jointly distributed random variables method," Sci. Iran., vol. 19, no. 3, pp. 423-429,(2012).
25. A. Johari and A. R. Khodaparast, "Modelling of probability liquefaction based on standard penetration tests using the jointly distributed random variables method," Eng. Geol., vol. 158, pp. 1-14, (May 2013).

26. A. Johari, A. A. Javadi, M. H. Makiabadi, and A. R. Khodaparast, "Reliability assessment of liquefaction potential using the jointly distributed random variables method," Soil Dyn. Earthq. Eng., vol. 38, pp. 81-87, (2012). 